\title{
Ocular Surface Pain: A Narrative Review
}

\author{
Divy Mehra $\cdot$ Noah K. Cohen · Anat Galor (D)
}

Received: May 7, 2020 / Published online: June 5, 2020

(c) The Author(s) 2020

\section{ABSTRACT}

Ocular surface pain is a frequent cause of visits to an eye care provider and has a substantial impact on healthcare cost, yet a complete understanding of its causative factors and tools for diagnostic workup are notably missing in many eye clinics. The cornea has the densest sensory innervation in the human body and has the potential to be a powerful producer of pain. Pain can manifest as a result of a noxious stimulus or disruption in the ocular surface anatomy (nociceptive pain), or it can result from abnormalities in the ocular surface neurosensory apparatus itself (neuropathic pain). Novel advances in neurobiology have sought to differentiate the two entities, particularly to identify when chronic dry eye symptomatology is driven by neuropathic ocular pain. In this review, we seek to provide an overview of the prevalence, physiologic factors, and management of ocular surface pain complaints.

Digital Features To view digital features for this article go to https://doi.org/10.6084/m9.figshare.12377873.

D. Mehra · A. Galor ( $\square)$

Surgical Services, Miami Veterans Affairs Medical Center, Miami, FL, USA

e-mail: agalor@med.miami.edu

D. Mehra · N. K. Cohen · A. Galor

Bascom Palmer Eye Institute, University of Miami,

Miami, FL, USA
Keywords: Dry eye; Neuropathic pain; Nociceptive pain; Ocular pain; Ocular surface pain

\section{Key Summary Points}

Ocular surface pain is a common cause of visits to eye care practitioners, frequently presenting within the scope of other ocular conditions such as dry eye, with substantial implications on global quality of life and healthcare cost.

Ocular surface pain may arise directly from tissue damage at the ocular surface or from changes to peripheral or central nerves in the ocular surface sensory pathway.

The trigeminal subnuclei have emerged as significant players in the modulation of ocular surface sensations, as explored in several animal models.

Several risk factors have been associated with ocular surface pain, including Sjögren's, graft versus host disease, migraine, fibromyalgia, refractive surgery, and environmental conditions. 
The treatment of refractory chronic ocular surface pain should address the underlying contributors in an individual patient. In some cases, the use of therapies that modulate nerve function should be considered.

\section{INTRODUCTION}

Interest in ocular surface pain has intensified in recent years, given that it is a common reason for presentation or referral to an eye care provider, has immense cost implications, and impacts quality of life (QoL). A detailed pain assessment is an essential part of a comprehensive eye examination. Subjective pain descriptors may include dryness, discomfort, grittiness, itchiness, burning, stabbing, shooting, or aching pain [1], and these conditions may occur spontaneously or be exacerbated by environmental insult, such as wind, light, or temperature changes. In the setting of an acute trauma, surgery, or infection, pain is ordinarily transient, and resolution of pain promptly follows treatment of the underlying condition. However, at times, pain may persist, either due to continued stress on the ocular surface or to nerve abnormalities, or both [2].

The International Association for the Study of Pain (IASP) defines pain as "an unpleasant sensory and emotional experience associated with actual or potential tissue damage" and pain is commonly stratified into two broad groups-nociceptive and neuropathic pain. Nociceptive pain refers to direct activation of nociceptors due to actual or threatened damage to non-neural tissue and implies an intact somatosensory nervous system [3]. In the eye, this is typically associated with transient pain following injury, surgery, or infection. Neuropathic pain is caused by a lesion or disease of the intrinsic somatosensory nervous system, often in the absence of other tissue injury. Investigation into the pathophysiology of neuropathic pain is ongoing in several prevalent disease states, including fibromyalgia, irritable bowel syndrome, vulvodynia, interstitial cystitis, and atypical facial pain disorders [4]. Interestingly, many individuals with these comorbidities also have chronic ocular surface pain $[5,6]$. In fact, similar to these chronic pain conditions outside the eye, neuropathic ocular pain (NOP) often presents with pain out of proportion to clinical signs.

The aim of this review was to provide eye care providers with a detailed overview of ocular surface pain, with a focus on epidemiology, neuro-pathophysiology, diagnosis, and treatment. Irregularities in other parts of the eye, such as neuritis, scleritis, and acute glaucoma, may also be associated with pain, but are beyond the scope of the current review. Articles for this review were compiled from the National Library of Medicine MEDLINE database, with a search in PubMed with the keywords "ocular surface pain"; searches were limited to articles written in English. This article is based on previously conducted studies and does not contain any studies with human participants or animals performed by any of the authors.

\section{EPIDEMIOLOGY}

Information on the epidemiology of ocular surface pain is often hidden within the literature on dry eye (DE), as one of the major symptoms of DE is ocular surface pain, characterized not only as dryness, but also as discomfort, burning, itchiness, irritation, and photophobia (evoked pain to light), to name a few $[1,7]$. Dry eye symptoms, including pain, are a leading cause of visits to eye clinics and ophthalmic healthcare costs [8]. Ocular surface pain has a negative impact on QoL, impacting both physical and mental functioning [9]. It has been associated with insomnia [10], poor coping mechanisms [11], and impaired social functioning [7], and the implications stretch to activities of daily living, such as reading, driving, and computer function, in addition to decreased occupational productivity and missed work [7]. Fortunately, recent advancements in the understanding of the pathophysiology of neurobiology of ocular surface pain may lead to novel therapies to alleviate individual and societal burden. 


\section{Prevalence}

\section{Symptoms of Ocular Surface Pain in the General Population}

As mentioned in the preceding section, data on the prevalence of ocular surface pain is generally extrapolated from the DE literature. Several population-based studies have investigated the prevalence of subjective ocular surface symptoms. The Blue Mountains Eye Study collected door-to-door data asking residents to complete a questionnaire on self-reported ocular symptoms. Of the 1174 Australian residents aged 49 years and older who responded, a positive response to mild, moderate, or severe grittiness was reported by approximately $25 \%$ and eye discomfort was reported by approximately 30\% [12]. Another population-based study of 926 volunteer Melbourne residents asked individuals to self-report and grade ocular discomfort, foreign body sensation (FBS), itching, dryness, and photophobia. In this group, mild, moderate, or severe discomfort was reported by $32 \%$ of individuals, FBS by $26 \%$, itching by $40 \%$, dryness by $17 \%$, and photophobia by $50 \%$ [13].

A high prevalence of ocular pain symptoms was also found in the UK. One study utilizing the TwinsUK adult registry extrapolated data from the Ocular Surface Disease Index (OSDI), a 12 -item scale that is used to assess DE syndrome (range 0-100) [14]. The first three questions of the OSDI represent the 'ocular symptoms pain domain' as they ask about eyes that are sensitive to light (question 1), eyes that feel gritty (question 2), painful or sore eyes (question 3), with frequency graded from 0 (never) through 4 (all of the time) during the past week [15]. In this cross-sectional study, 689 women completed the OSDI, of whom $17.1 \% \quad(n=118)$ reported OSDI pain symptoms in the past week, as calculated by a sum score of $\geq 3$ for the first three OSDI questions [14].

Similar data has been found in the USA. Two large-scale surveys evaluated the prevalence of ocular dryness and irritation in US populations of female and male healthcare professionals. Of the 36,995 women participating in the Women's Health Study survey (ages 45 through 84 years), dryness was experienced constantly in $381(1.0 \%)$, often in $2109(5.7 \%)$, and sometimes in $10,474(28.3 \%)$. In this same group, symptoms of irritation were reported constantly in 207 (0.6\%), often in $2102(5.7 \%)$, and sometimes in $18,901(51.1 \%)$ [16]. The Physicians' Health Studies surveyed 25,444 male healthcare workers aged $>50$ years. Dryness was reported constantly in 204 (0.8\%), often in $924(3.6 \%)$, and sometimes in 4716 $(18.5 \%)$; irritation was reported constantly in $126(0.5 \%)$, often in $1050(4.1 \%)$, sometimes in $10,622(41.8 \%)$ [17]. A comparison of data between the two studies reveals a higher frequency and severity of ocular dryness and irritation in women than in men [16-18]. In another US population-based study, 2482 volunteers aged 65 to 84 years in Salisbury, Maryland were asked about self-reported frequency of dryness, grittiness, and burning. Among these individuals, 22\% reported dryness, 33\% grittiness, and $25 \%$ burning sometimes, often, or all the time [19].

The above numbers were generated by studying the general population and not individuals seeking eye care. Thus, the results of these studies highlight that a significant proportion of the general population has some degree of ocular surface pain, some or all of the time.

\section{Risk Factors and Associations}

Acute ocular surface pain commonly occurs due to local tissue injury in the setting of trauma, surgery, and infection $[2,20]$. Many factors have been associated with chronic ocular surface pain, including congenital or acquired anatomical abnormalities of the eyelids (i.e., entropion, ectropion) and conjunctiva (i.e., conjunctivochalasis, pterygium), and systemic, iatrogenic, and environmental factors [21-23].

Considering systemic associations, immune disorders have been most closely linked to chronic ocular surface pain, namely, Sjögren's syndrome and graft-versus-host disease (GVHD). Sjögren's syndrome is an autoimmune disease in which lymphocytic infiltration injures the lacrimal gland, leading to disruptions in the tear film [24]. In a study of 224 individuals with primary Sjögren's syndrome in 
Nantong, China, the mean overall OSDI score (0-100) was 25 , with an average 'OSDI symptoms domain' score of 29 (calculated using the first five questions of the OSDI that include pain and visual complaints, range 0-100). The study further grouped individuals by location and found higher OSDI scores in inpatients $(n=127)$ versus outpatients $(n=97)$ (30 vs. 18 ; $p<0.001$ ) [25]. In another study of 18 individuals with primary or secondary Sjögren's syndrome, OSDI symptom severity negatively correlated with lissamine green corneal staining $(r=-0.43, p=0.01)$ [26], suggesting a reduction in reported symptoms with increasing ocular surface damage and providing evidence for discrepancies between ocular surface pain and DE signs $[27,28]$. Chronic graft-versus-host disease (cGVHD) is also associated with chronic ocular surface pain. cGVHD commonly occurs after hematopoietic stem cell transplantation (HSCT). In 136 individuals who underwent HSCT and who did not have a prior diagnosis of DE, mean OSDI scores increased post- versus pre-HSCT (20 vs. $2.6 ; p<0.001$ ), with the most common primary complaints being dryness/FBS $(n=27)$, blurred vision $(n=20)$, and photophobia $(n=6)$ [29]. These above studies point to chronic immune activation as one cause of chronic ocular surface pain.

Chronic non-ocular pain conditions have also been linked to chronic ocular surface pain. For example, individuals with migraine frequently report symptoms of ocular discomfort [32]. In a study of 250 individuals at the Miami Veterans Affairs Hosptial, ocular symptom profiles were compared between individuals with and without migraine (31 vs. 219 individuals, respectively). Those with migraine had a higher intensity of ocular surface pain compared to controls (mean \pm standard deviation [SD]: OSDI $54 \pm 22$ vs. $36 \pm 23, p=0.0001$; Neuropathic Pain Symptom Inventory modified for the eye [NPSI-Eye] [33] $39 \pm 23$ vs. $22 \pm 20, p=0.0001$ ) but similar ocular surface findings [34]. Other pain conditions linked to ocular surface pain include chronic muscle/back pain, fibromyalgia, and chronic pain syndromes (CPS) $[27,35,36]$. In a German study of 90 individuals who were asked to report eye pain on a numerical rating scale (NRS) with a range of 0 to
10,44 of $66(67 \%)$ individuals with fibromyalgia reportred a mean eye pain rating of 2.6 , and 15 of $24(63 \%)$ individuals with chronic musculoskeletal pain reported a mean eye pain rating of 1.8 [36]. The most frequent eye pain descriptors were itchiness $(\sim 60 \%)$, annoying ( $\sim 50 \%)$, and tiring $(\sim 45 \%)$. These numbers were presumed to be higher than the frequency of ocular surface pain in the general German population [36]. In a US study, 154 individuals were clustered into groups based on number of chronic non-ocular pain conditions. 'High CPS' ( $n=97)$ was defined as $\geq 3$ conditions and 'Low CPS' $(n=57)$ was defined as $0-2$ conditions. The High CPS group reported significantly worse ocular surface pain over the prior week compared to the Low CPS group (NRS 0-10: 4.5 vs. $2.9 ; p<0.0005)$. In addition, the High CPS group reported a higher intensity of neuropathic pain-like eye symptoms compared to the Low CPS group, assessed using the NPSI-Eye (29 vs. $19 ; p=0.006$ ) [6]. The above data reinforce the notion that chronic ocular surface pain can co-exist with a number of non-ocular pain conditions.

Other systemic conditions associated with chronic ocular surface pain include trigeminal neuralgia, benign essential blepharospasm (BEB), small-fiber polyneuropathies, diabetic neuropathy, and chemotherapy and radiation [37]. For example, trigeminal neuralgia (TN) is a chronic pain condition that presents with craniofacial pain in the distribution of the trigeminal nerve. TN is characterized by brief, sharp electric-shock-like paroxysmal pain arising from one or more trigeminal nerve branches (V1, V2, or V3). Attacks are commonly initiated by mild mucocutaneous stimulation-such as brushing teeth or chewing motion-in the affected nerve field, known as the trigger zone. Most cases are primary or idiopathic, although intracranial compression and traction are known secondary causes. Although TN most commonly presents with pain in the $\mathrm{V} 3$ region (jawline/lower lip area), it can present with pain at the level of $\mathrm{V} 1$ and the corneal surface [37-39]. BEB is a condition characterized by abnormal blinking or spasms of the eyelids that is frequently associated with ocular surface symptoms. In a prospective case series, 40 
individuals with DE (Dry Eye Workshop severity grading score $\geq 1$ [30]) and BEB were compared to 40 individuals with DE alone and 40 controls. Individuals with DE and BEB reported significantly higher DE symptoms via the OSDI $(35 \pm 7)$ compared to individuals with DE alone $(19 \pm 3 ; p=0.002)$ and healthy controls $(\sim 9 \pm 1 ; p<0.001)$ [31]. These data demonstrate that BEB may be an independent contributor to ocular surface pain.

Iatrogenic factors, such as chronic glaucoma medication use [40] and refractive surgery [41], have also been associated with chronic ocular surface pain. In a cross-sectional study of 62 predominantly male Miami veterans with glaucoma, individuals using three or more glaucoma medications reported a higher incidence of shooting pains compared to those on less than three medications $(28 \%$ vs. $4 \%$, $p=0.03)$. Patients on three or greater topical glaucoma drops were also more likely to experience ocular dryness $(67 \%$ vs. $38 \% ; p=0.04)$ and itchiness $(74 \%$ vs. $44 \% ; p=0.02)$ than those on fewer medications [42]. Chronic ocular surface pain has also been associated with refractive surgery [43]. Dry eye symptoms are common in the first month post photorefractive keratectomy (PRK) [41] or laser in-situ keratomileusis (LASIK), typically with resolution over the following months, according to the Patient Reported Outcomes With LASIK (PROWL) study [44]. In the PROWL-1 study, the mean OSDI of 215 patients was significantly less at the six-month post-op period compared to pre-procedure baseline ( 8 vs. $14, p<0.001$ ) [44]. However, rare cases have been documented of persistent refractory ocular surface pain, light sensitivity, and visual difficulty after surgery, often in the absence of ocular surface signs or other triggers $[45,46]$. These cases suggest that chronic ocular surface pain can develop after refractive procedures.

Environmental factors have also been associated with ocular surface pain, particularly exposure to gaseous air pollution $[47,48]$. In a study of 55 healthy volunteers in Sao Paulo, Brazil, subjects kept a nitrogen dioxide $\left(\mathrm{NO}_{2}\right)$ passive monitoring system beside them for 1 week as a proxy for exposure to air pollution and completed symptom questionnaires. Total daily $\mathrm{NO}_{2}$ exposures were categorized into four quartiles (Q1-Q4) of increasing daily exposure. A dose-dependent pattern was found between daily $\mathrm{NO}_{2}$ exposure and OSDI $(p=0.01)$, with a mean OSDI of approximately 8 for Q1, approximately 20 for Q2, approximately 22 for Q3, and approximately 30 for Q4. In addition, symptoms of ocular irritation were found in $38.5 \%$ of individuals in Q1, 64\% of those in Q2, 71\% of those in Q3, and 93\% of those in Q4. Similar findings have been described in the setting of ozone exposure [49]. These data suggest associations between exposures to noxious environmental insults and ocular surface discomfort [48].

The results of these studies substantiate associations between several systemic conditions, iatrogenic therapies, and environmental exposures with chronic ocular surface pain.

\section{ANATOMY, PHYSIOLOGY, AND PATHOPHYSIOLOGY}

The pathways of ocular surface pain involve both peripheral and central nerves [20]. The peripheral nerves arise from the richly innervated cornea and ocular surface. Free nerve endings within the superficial corneal epithelium play an important role in the detection of environment stimuli but are susceptible to damage $[50,51]$. The cornea contains different types of nociceptive (or pain) fibers, or nociceptors, encompassing all peripherally located neurons preferentially sensitive to noxious stimuli. These neurons demonstrate dynamic stimulus-response behavior to prolonged stimulation [52]. With the assistance of animal studies, explorations into the neurobiology of the corneal sensory pathways (referring to the sum network of peripheral and central neurons involved in the processing and modulation of ocular surface sensation) have attempted to clarify the role of primary (peripheral) and second- and third-order (central) neurons in the pathophysiology of ocular surface pain. Studies in animals have broadened our understanding of different corneal nociceptive fiber types [53], nerve terminal ion channels [20], and sensory 
interpretation of the trigeminal nucleus $[54,55]$.

\section{Corneal Neuroanatomy and Physiology}

The cornea is richly innervated with A-delta and C-fiber primary afferents, which are branches of the nasociliary nerve, itself a branch of the ophthalmic division of the trigeminal nerve, known as CN V1 (first division of fifth cranial nerve); thus, the somas of these corneal nociceptors lie in the trigeminal ganglion [56-58]. Nasociliary nerve branches enter the peripheral cornea radially, losing their myelin sheath at approximately $1 \mathrm{~mm}$ from the limbus, before migrating anteriorly to penetrate the Bowman's layer and forming the subbasal nerve plexus $[37,56,58]$. Nociceptive free nerve endings are intimately bound to the epithelial cell borders, even those of apical layers, thereby explaining the ability of a variety of peripheral noxious stimuli (i.e., fumes, abrasions) to cause ocular surface pain [50].

Different nociceptor fibers respond to different environmental stimuli and include mechanoreceptors $(\sim 20 \%$ of total corneal sensory nerves), polymodal receptors $(\sim 70 \%)$, and cold receptors $(\sim 10 \%)$ [59]. As reviewed by Belmonte and Gallar, mechanoreceptors are responsible for the sharp pain felt upon mechanical stimulation, such as an object contacting the cornea, and are the fastest conductors of the three types of receptors. Polymodal receptors respond to mechanical, thermal, chemical, and $\mathrm{pH}$ changes. The aptly named cold nociceptors transmit information related to drops in temperature, for example, in evaporative cooling, and also changes in tear osmolarity $[53,60]$. Pricking pain is most associated with mechanoreceptors, burning/stinging pain with polymodal receptors, and dryness with cold receptors [20].

Specific proteins and channels help identify these various nociceptors; these include Piezo2 in the cell body of the trigeminal ganglion and terminal nerve endings of corneal mechanoreceptor afferents [61]; TRPA1 and TRPV1, ion channels that respond to chemical and thermal changes at the terminal nerve endings of polymodal neurons; and TRPM8, an ion channel which senses evaporation on the terminal nerve endings of thermoreceptors [20, 62]. Expression of these channels is influenced by reactive oxygen species, lipid peroxidation products [20], and local inflammatory mediators (i.e., adenosine triphosphate, prostaglandins, matrix metalloproteinase 8, bradykinin, histamine, immune cell cytokines) [63], neurotrophic factors (i.e., nerve growth factor) [64], and neuropeptides (i.e., calcitonin gene-related peptide [CGRP], substance P) $[20,56,65]$.

\section{Corneal Primary Afferent Pathophysiology}

The IASP defines sensitization as the "increased responsiveness of nociceptive neurons to their normal input, and/or recruitment of a response to normally subthreshold inputs" [3]. Several studies have found that peripheral nociceptors can become sensitized when exposed to a variety of insults. Inflammatory damage, noxious stimuli, and hyperosmolarity directly activate corneal nociceptors, with accompanying changes in terminal ion channel expression and activity through gene expression, cytosolic signaling, and transcription factors. These changes are characterized by reduced activation thresholds and consequently increased excitability $[66,67]$. This phenotypic change at the level of the corneal nociceptor or first-order neuron, though potentially reversible, is termed peripheral sensitization.

Neural responses and changes in the firing pattern of peripheral nociceptors have been recorded in response to particular environments. One study evaluated cold thermoreceptors and polymodal nociceptor nerve terminal impulse (NTI) activity in mice following exposure to solutions of differing osmolality (325-$1005 \mathrm{mOsm} / \mathrm{kg}$ ) as well as to an "inflammatory soup" solution (bradykinin, histamine, prostaglandin $\mathrm{E}_{2}$, serotonin, and ATP) to mimic inflammatory conditions in vivo [68]. At a constant basal corneal temperature of $33.6^{\circ} \mathrm{C}$, NTI activity was significantly increased in cold thermoreceptors in a linear relationship to 
osmolality (0.34 imp per second/10 mOsm) once osmolality surpassed $340 \mathrm{mOsm}$. On the other hand, polymodal nociceptors in increasingly hyperosmolar exposures only activated with hyperosmolarities of $\geq 600$ mOSM and then in a nonlinear, irregular fashion characterized by flattened NTI waveform shapes. In the same study, exposure to an "inflammatory soup" in iso-osmolal saline at $33.6{ }^{\circ} \mathrm{C}$ significantly increased polymodal receptor NTI frequency (from 0.10 to $0.19 \mathrm{imp}$ per second; $p=0.003$ ), with no further increase in NTI activity following osmolality increases. These results suggest that cold thermoreceptor activity is more influenced by tear osmolality and polymodal nociceptors by inflammatory mediators [68]. Both elevated osmolarity and the presence of inflammatory mediators are often present on the ocular surface of humans with tear abnormalities.

Studies have also reported that corneal nociceptors undergo a change in function following surgical injury. In a rat model of unilateral lacrimal gland removal, tear production decreased by $35 \%$ and spontaneous blink rate increased fourfold at 1 week after surgery compared to baseline [69]. Menthol application (which activates cold thermoreceptors) evoked a 1.4-fold greater peak neuronal firing frequency in animals with removed lacrimal glands compared to controls $(p<0.05)$. In a similar manner, measurements of neuronal firing activity in response to rising temperatures were used to determine the cooling threshold (defined as baseline activity plus 3 standard deviations); the cooling threshold was also significantly higher $\left(31.5\right.$ vs. $\left.29.9{ }^{\circ} \mathrm{C} ; p<0.05\right)$ [69]. This study provides evidence that changes in ocular surface conditions, such as in aqueous tear deficiency, result in phenotypic changes in corneal nociceptor response and sensitivity.

These experimental models provide valuable insight into the normal and pathologic physiology of the corneal neurosensory system. The studied models replicate several facets of human disease, including aqueous tear deficiency and ocular surface inflammation. A limitation in animal models is that pain cannot be directly assessed. However, secondary markers of pain have been studied as a proxy for subjective symptoms. Eye wiping, or the purposeful wiping of the face by the ipsilateral forelimb, is one such test for acute ocular irritation-related behavior in rats. In a study of eye wipe behavior in rats, drops of $\mathrm{NaCl}$ of varying concentrations $(0.15,1,2,3,5 \mathrm{M})$ placed onto one eye resulted in a linear dose response relationship with eye wipes within the next $30 \mathrm{~s}(F=24.96, p<0.01)$ [70]. Further, treatment with $10 \mathrm{mg} / \mathrm{kg}$ morphine completely eliminated eye wipe behavior in rats given $5 \mathrm{M} \mathrm{NaCl}$, while lower morphine concentrations $(1,2,4,8 \mathrm{mg} / \mathrm{kg})$ resulted in dose-dependent reductions in eye wipes [70]. Taken together, these studies suggest that abnormal tear composition, such as elevated osmolarity, can cause ocular surface pain.

\section{Central Nerves in the Ocular Sensory Apparatus}

The cell bodies of corneal pain receptors are located in the trigeminal ganglion, with fibers from the first-order trigeminal nerve synapsing in the trigeminal subnucleus caudalis/upper cervical transition zone $\left(\mathrm{Vc} / \mathrm{C}_{1-2}\right)$ as well as the subnucleus interpolaris/subnucleus caudalis $(\mathrm{Vi} / \mathrm{Vc})$ [50]. Second-order axons travel from the spinal trigeminal nuclear complex, decussate, and terminate in the thalamus alongside contralateral spinothalamic fibers. Third-order neurons carry information from the thalamus to precisely localized areas of the primary somatosensory cortex [50, 71] (Fig. 1). There is also an important component of pain modulation originating from the descending pathways of the limbic system, midbrain, and thalamus; descending signals travel through periaqueductal grey to the brainstem, modulating pain signals and continuing to the trigeminal nuclear complex $[50,56]$.

\section{Central Nerve Pathophysiology}

According to the IASP, central sensitization refers to the "increased responsiveness of nociceptive neurons in the central nervous system to their normal or subthreshold afferent input" [3]. Physiologic changes in central neurons that define sensitization include reduced activation 


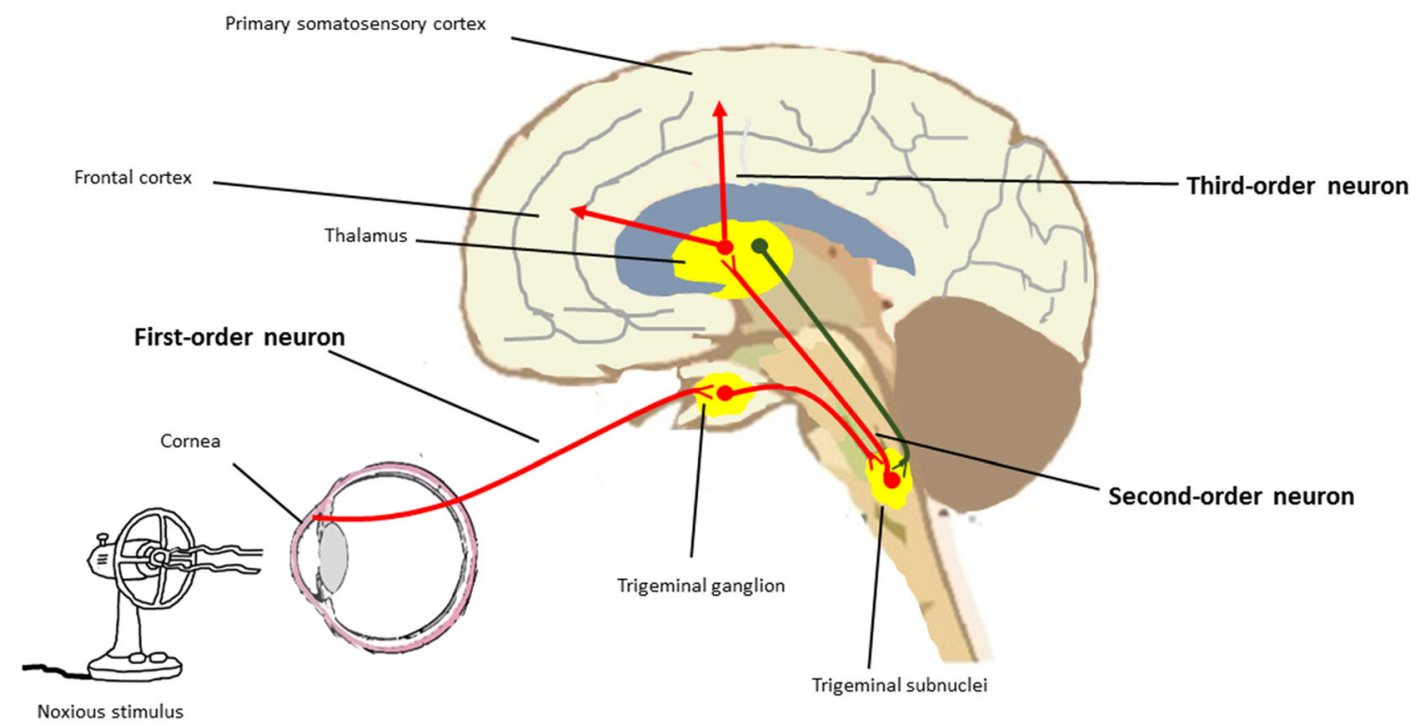

Noxious stimulus

Legend

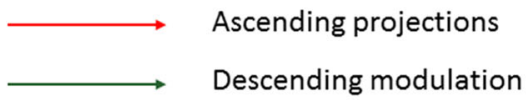

Fig. 1 A simplified depiction of the ocular surface sensory pathway. Neuronal cell bodies of corneal nociceptors are located in the trigeminal ganglion. These first-order neurons synapse at the trigeminal subnucleus caudalis/ upper cervical transition zone and the subnucleus interpolaris/subnucleus caudalis. Second-order neurons project

thresholds and increased excitability. These changes can explain why ocular surface pain is often disproportionate to ocular surface pathology and largely unaffected by topical treatments [56]. Many factors can lead to changes in central neurons, including persistent peripheral nociceptive traffic and surface inflammation [72, 73], abnormalities in descending inhibitory control [67], or changes in local circuit neurons and microglia [74], among other proposed mechanisms. Several experiments have demonstrated that central nerve changes can occur in the corneal sensory pathways.

\section{Trigeminal Subnuclei in Rat Models}

In one animal model, rats were exposed to ultraviolet irradiation (UVR), which produced a phenotype of photokeratitis, including signs of scleral hyperemia, corneal opacities, and pupil from trigeminal subnuclei to the thalamus, and third-order neurons terminate in the primary somatosensory cortex and other cortical areas. The thalamus also projects descending inhibitory fibers that are involved in neural pain modulation

dilation, hours after irradiation that gradually diminished over 7 days. Eye wipes, induced by hypertonic saline, were quantified as a proxy for ocular surface pain. At 2 days following UVR $\left(300 \mathrm{~mJ} / \mathrm{cm}^{2}\right)$ exposure, exposed rats had a higher eye wipe frequency (per $5 \mathrm{~min}$ ) after the application of hypertonic saline $(5 \mathrm{M})$ to the cornea compared to control animals ( $\sim 24$ vs. $\sim 13 ; p<0.01$ ), Concomitantly, at 2 days after exposure, hypertonic saline also evoked significantly elevated neural response activity (measured by total response magnitude [Rmag]) of superficial laminae in the $\mathrm{Vc} / \mathrm{C}_{1}$ region compared to controls ( $\sim 900$ spikes/stimulation vs. $\sim 300$ spikes/stimulation; $p<0.01$ ). Interestingly, no change in activity was noted in the $\mathrm{Vi}$ / $\mathrm{Vc}$ region [55]. These findings suggest a role for $\mathrm{Vc} / \mathrm{C}_{1}$ but not $\mathrm{Vi} / \mathrm{Vc}$ in neural processing of UVR and mechanistically explains the 
cutaneous hyperalgesia that often accompanies UVR-induced damage $[55,56]$.

In another study, the $\mathrm{Vi} / \mathrm{Vc}$ and $\mathrm{Vc} / \mathrm{C}_{1}$ subnuclei of rats were each selectively activated using microinjections of glutamate to determine which stimulation site would lead to tearing. In this study, local stimulation of the $\mathrm{Vi} / \mathrm{Vc}$ region, but not the $\mathrm{Vc} / \mathrm{C}_{1}$ region, resulted in significant increased tear volume (milligram per 2 min) collected and measured 2 min after administration $(\sim 1.7 \quad$ vs. $\sim 0.3 ; p<0.001)$ [54]. Vi/Vc neurons may be grouped into type I and type II units; type I units are defined by a monophasic dose-dependent excitation response to carbon dioxide $\left(\mathrm{CO}_{2}\right)$ pulses at the ocular surface [75] while type II units are defined by a biphasic response [75]. Type II units are thought to be moisture sensitive and to have a role in detection of ocular surface dryness. In the same study, spontaneous neural activity at the type II units of the $\mathrm{Vi} / \mathrm{Vc}$ region was inhibited following application of artificial tears at the ocular surface $(>75 \%$ decrease from background; $p<0.01)$. Ten minutes after artificial tear application, eyelid retraction and filter papers were used to dry the ocular surface, resulting in a prompt increase in type II Vi/Vc unit spontaneous activity to pre-wet levels. No changes were noted in the $\mathrm{Vc} / \mathrm{C} 1$ region in response to wetting or drying, pointing to the role of $\mathrm{Vi} / \mathrm{Vc}$ in moisture sensation and tear control [54]. These two studies reveal distinct functions of the $\mathrm{Vc} / \mathrm{C}_{1}$ and $\mathrm{Vi} / \mathrm{Vc}$ subnuclei in sensory processing.

Dysfunctional descending pain modulation may also play a role in chronic ocular surface pain, as is also seen in other chronic pain syndromes [59]. Descending inhibitory activity is thought to originate from the thalamus and reticular system to stimulate central gammaaminobutyric acid (GABA) receptors, regulate interneurons, and ultimately modify ascending pain signals at the level of the trigeminal nucleus [76, 77]. In a study of male rats, the neural activities of the $\mathrm{Vi} / \mathrm{Vc}$ and $\mathrm{Vc} / \mathrm{C}_{1}$ subnuclei were monitored using microelectrodes following microinjections of muscimol, a $\mathrm{GABA}_{\mathrm{A}}$ receptor-selective agonist. To test for intersubnuclear communication, local muscimol microinjections were localized to the rostral Vi/
Vc transition region. In seven of the eight trials, spontaneous neural activity at both the $\mathrm{Vc} / \mathrm{C}_{1}$ and $\mathrm{Vi} / \mathrm{Vc}$ subnuclei was decreased by $\geq 50 \%$ with partial reversal following administration of bicuculline methiodide, a $\mathrm{GABA}_{\mathrm{A}}$ antagonist [78]. These results suggest that $\mathrm{GABA}_{\mathrm{A}}$ receptor mechanisms play a role in the modulation of neural transmission at the level of second-order trigeminal neurons. These animal studies provide valuable information about central pain processing at the level of the trigeminal subnuclei.

\section{Central Pain Processing and Functional Magnetic Resonance Imaging}

Corneal pain sensation has been mapped out to its corresponding location on the primary somatosensory cortex (S1) using functional magnetic resonance imaging (fMRI) [71]. The basis of fMRI is to detect local changes in oxygenation concentration (blood oxygen level dependent [BOLD] contrast) related to increased neural activity [79]. In a case study in Massachusetts, neuroimaging using fMRI was performed on an individual with photophobia due to a hard-contact lens-associated abrasion and compared to imaging after recovery, 9 days later [80]. Bright light (6-s blocks, $65 \mathrm{~lx}$ ) produced pain and blinking at the time of abrasion and blinking alone after recovery. At the time of abrasion, several brain areas were activated in response to light, including the contralateral middle of the superior-inferior extent of S1 and bilateral primary motor cortices (M1) at regions parallel to S1. After recovery, light activated the bilateral M1 regions but not the S1 region [71]. Bright light stimulation during the abrasion also produced specific activation patterns in the ipsilateral trigeminal ganglion, bilateral trigeminal nucleus caudalis, contralateral ventroposteromedial thalamus, anterior cingulate cortex, and middle frontal gyrus. These areas were no longer activated with bright light after recovery [80]. This study elegantly localizes central areas involved in ocular surface pain processing in humans. 


\section{CLINICAL EVALUATION AND DIAGNOSIS}

Similar to other eye pathologies, the diagnosis of ocular surface pain requires a thorough history and clinical examination. Particular attention is paid to chronicity, pain in relation to clinical signs, and subjective descriptors of pain such as "burning" or "sensitivity to wind and light" in order to distinguish nociceptive and neuropathic etiologies [4].

\section{Nociceptive Pain at the Ocular Surface}

The ocular surface pain evaluation begins by examining for sources of nociceptive pain. These include abnormalities of the eyelids, conjunctiva, and tear film. In the eyelids, particular attention should be paid to the presence of ectropion, entropion, trichiasis [81, 82], lagophthalmos [83], laxity [84], and rosacea [85]. In the conjunctiva, the presence of conjunctivochalasis, pterygium, or superior limbic keratoconjunctivitis must be evaluated $[21,86]$. A tear film exam should evaluate tear production and volume, which are reduced in aqueous tear deficiency (ATD), and tear break-up time, which is reduced in both ATD and evaporative DE. In addition, the presence of corneal and conjunctival staining should be assessed with the appropriate vital dyes.

\section{Neuropathic Pain at the Ocular Surface}

Neuropathic ocular pain is a clinical diagnosis that can be made when ocular surface pain persists after nociceptive sources of pain are diagnosed and treated. There are no universal diagnostic criteria for neuropathic ocular pain $[2,21]$. However, some clues can be used to suggest the presence of a neuropathic source to pain.

\section{Symptoms Associated with NOP}

First, certain pain descriptors, including symptoms of allodynia and hyperalgesia, are more commonly seen in neuropathic versus nociceptive pain [37]. The IASP defines allodynia as "pain caused by a stimulus that does not normally provoke pain," while hyperalgesia is "increased pain from a stimulus that normally provokes pain" [3]. Based on these definitions, neuropathic pain-specific questionnaires have been developed for the assessment of pain outside the eye [87]. As briefly mentioned in section Risk Factors and Associations, one such questionnaire is the Neuropathic Pain Symptom Inventory (NPSI), which investigates for the presence and intensity of different neuropathic pain symptoms (spontaneous ongoing pain, paroxysmal pain, evoked pain, and paresthesias/dysesthesias) [87]. We modified the NPSI for use in the eye (NPSI-Eye), changing evoked pain triggers to ones relevant for the eye; that is, cutaneous stimuli in the original NPSI (i.e., brushing, pressure, and contact with cold) were revised to known hyperalgesic/allodynic triggers in the eye (wind, light, and contact with something hot or cold). In a study of 397 predominantly male Miami veterans with ocular surface pain (NRS $0-10: \geq 1$ on average in the past week), correlations were found between NPSI-Eye scores and general eye pain indicators, such as the NRS $(\rho=0.69, p<0.001)$ and the short form McGill Pain Questionnaire (sf-MPQ) $(\rho=0.65, p<0.001)$. Furthermore, NPSI-Eye scores were significantly higher in individuals suspected to have central ocular pain involvement (based on "no or partial response" after placement of topical anesthesia to pain) compared to those with "complete response" with anesthetic $(40 \pm 24$ vs. $27 \pm 21 ; p<0.05)$. These data suggest preliminary validation of the NPSI-Eye as a tool for the assessment of NOP [33].

The Ocular Pain Assessment Survey (OPAS) is another ocular pain questionnaire that focuses on overall pain, not only on the neuropathic features of pain [37]. OPAS assesses pain in the past $24 \mathrm{~h}$ and past 2 weeks and includes numerical scales for pain intensity, frequency, QoL impact, preoccupation with pain, aggravating and alleviating factors, and associations. OPAS has questions on non-eye pain intensity, frequency, and preoccupation. In a study of 102 individuals at the Massachusetts Eye and Ear Infirmary, the OPAS was used to evaluate ocular 
pain in individuals with and without eye pain of various etiologies, before and after treatment. Validity and internal consistency of the OPAS were determined using the Wong-Baker FACES ${ }^{\circledR}$ Pain Rating Scale (0-10 scale) as the gold standard method [88]. The OPAS was found to have criterion validity at both initial $\left(r_{\mathrm{s}}=0.71, n=102, p<0.01\right)$ and post-treatment follow-up visits $\left(r_{\mathrm{s}}=0.97, n=21, p<0.01\right)$, while 24-h ocular pain scores from the OPAS were sensitive $(94 \%)$, specific $(81 \%)$, and accurate $(91 \%)$ [88]. These data suggest that pain scales can be adapted to quantify ocular surface pain.

\section{Diagnostic Tests Used in the Evaluation of NOP}

Sensory testing can provide clues to whether ocular surface pain is caused by nerve abnormalities. Corneal sensitivity can be examined qualitatively with a cotton tip applicator or dental floss or quantitatively with Cochet-Bonnet and Belmonte aesthesiometers. Both hypo- and hyperesthesia to stimuli can be seen in individuals with NOP $[37,89]$.

\section{Aesthesiometry}

Simple tests for corneal sensation involve the applications of a cotton swab, the tip of a tissue, or unwaxed dental floss to the ocular surface. A numerical scale (NRS 0-3, referring to none, reduced, normal, and increased sensation) may be used to characterize and monitor sensation over time [90].

The Cochet-Bonnet aesthesiometer consists of a nylon monofilament extending up to $6 \mathrm{~cm}$ in length that is first brought into contact with the ocular surface and then retracted in $0.5-\mathrm{cm}$ increments until corneal sensation is felt [4]. In one Turkish study, 36 individuals with fibromyalgia but no known eye disease had higher corneal sensitivity in the central, superior, and inferior quadrants compared to 39 controls $(60.0$ vs. $55.0 \mathrm{~mm}[p=0.03]$ for central cornea; 57.5 vs. $50.0 \mathrm{~mm}[p=0.005]$ for superior cornea; 53.9 vs. $46.0 \mathrm{~mm}[p<0.001]$ for inferior cornea). OSDI scores were also higher in the fibromyalgia group compared to controls
(20 vs. $6 ; p<0.001$ ), with a positive correlation between OSDI and central corneal sensitivity scores $(r=0.44, p=0.007)$. However, no differences were found between the groups in relation to tear parameters (Schirmer I test 16.1 vs. $15.3 \mathrm{~mm}$; tear film breakup time 17.8 vs. $18.8 \mathrm{~s}$ ), and tear metrics did not relate to corneal sensitivity [27]. This correlation supports the association between corneal sensitivity and subjective reports of ocular surface pain, even in the absence of ocular surface signs. Limitations of the Cochet-Bonnet aesthesiometer include the need to touch the cornea and then sterilize the filament, sensitivity measures can be impacted by room humidity and temperature, sensitivity cannot be quantified past the fixed length of the filament, and only a mechanical stimulus can be induced [91].

The Belmonte aesthesiometer utilizes a noncontact air jet to provide the stimulus [4]. Mechanical (variable air flow), thermal (hot or cold pulses), and chemical (varying $\mathrm{CO}_{2}$ concentrations) stimuli can be administered to determine corneal sensitivities in all three corneal nociceptors. In a French study, 44 individuals with a prior diagnosis of $\mathrm{DE}$ were compared to 42 controls. Individuals with a DE diagnosis reported various symptoms assessed on a scale of $0-4$, including 'burning or sandy sensation' (mean $2.0 \pm 1.1$ ), 'stinging' (mean $1.9 \pm 1.2$ ), and 'itching' (mean $0.93 \pm 1.2$ ) while controls reported symptom scores of ' 0 ' for all three symptoms. Individuals with $\mathrm{DE}$ demonstrated significantly higher mechanical (153 vs. $109 \mathrm{~mL} / \mathrm{min})$, chemical $\left(23.9 \% \mathrm{CO}_{2}\right.$ vs. $\left.16.4 \% \mathrm{CO}_{2}\right)$, heat $\left(+0.34{ }^{\circ} \mathrm{C}\right.$ vs. $\left.+0.26{ }^{\circ} \mathrm{C}\right)$, and cold $\left(-0.14{ }^{\circ} \mathrm{C}\right.$ vs. $\left.-0.05^{\circ} \mathrm{C}\right)$ thresholds than controls using the Belmonte aesthesiometer (all $p<0.001)$ [92], indicating decreased sensitivity to a variety of stimuli. In contrast, a study of 129 Miami veterans with DE symptoms found inverse correlations between pain (NRS score, NPSI-Eye total and subscales) and corneal mechanical detection thresholds (log-transformed values) ( $r$ between -0.15 and -0.27 ) [93], indicating increased sensitivity to a mechanical stimulus. Taken together, these studies demonstrate that both higher and lower sensitivities can be seen in individuals with chronic ocular surface pain. Limitations of the 
Belmonte aesthesiometer is that it is not commercially available and thus requires in-house manufacturing, it is relatively large, and threshold testing takes a significant amount of time. Thus, the device is better adapted to the research, as opposed to the clinical, setting $[4,92]$.

\section{Topical Anesthetics in Distinguishing Central and Peripheral NOP}

Assessment of pain after the application of topical anesthetics is another important test in the evaluation of nerve abnormalities [2, 45]. Given that ocular surface pain arises from pathologic activation of central or peripheral origins, persistent pain after topical anesthesia suggests that pain arises from a central or nonocular surface source. The rationale for this assumption is that because topical anesthetics dampen peripheral inputs on the ocular surface, pain should be eliminated in individuals with ocular surface damage or peripheral sensitization as a source of pain [38]. In one study, 224 individuals with DE symptoms (Five-item Dry Eye Questionnaire [DEQ5] symptom score $\geq 6$ ) at the Miami Veterans Affairs Hospital were grouped by the presence of persistent ocular pain $15 \mathrm{~s}$ following application of topical anesthesia (proparacaine hydrochloride 0.5\%). Compared to individuals with complete pain resolution with anesthesia, those with persistent pain $(n=41)$ reported higher ocular pain intensity over the past week (assessed using NRS $0-10: 5.3 \pm 2.2$ vs. $3.4 \pm 2.3 ; p<0.0005)$ and had higher NPSI-Eye scores $(36 \pm 22$ vs. $23 \pm 21 ; p<0.0005)$. In addition, the group with persistent pain reported higher intensities of hot-burning pain $(4.9 \pm 3.2$ vs. $3.0 \pm 2.9$; $p<0.0005)$, sensitivity to light $(5.6 \pm 3.1$ vs. $3.2 \pm 3.2 ; p<0.005)$, and sensitivity to wind $(4.9 \pm 3.6$ vs. $2.9 \pm 3.1 ; p=0.02)$ [94]. These results suggest that centrally mediated pain is associated with higher levels of ocular pain intensity with a predilection for burning-type pain and evoked pain to wind and light $[45,94]$. A limitation of this test is that central pain cannot be distinguished from non-ocular surface origins of pain.

\section{Confocal Microscopy}

In vivo confocal microscopy (IVCM) has been used to evaluate for the presence of peripheral corneal nerve abnormalities. This technique allows noninvasive in vivo imaging of corneal cellular architecture, nearly at the level of histological visualization. The laser IVCM offers up to 800 -fold magnification, which can be used to examine and quantify cell characteristics and nerve density immediately below the basal epithelium (subbasal nerve plexus), at a depth of $50-80 \mu \mathrm{m}$, and in the stroma [95]. In a study in Nottingham (UK), 14 individuals (27 eyes) with severe, chronic ( $>1$ year) and refractory ocular pain in the absence of ocular surface signs were compared to seven healthy controls (14 eyes). Quantitative IVCM measures included sub-basal nerve density $\left(\mathrm{mm} / \mathrm{mm}^{2}\right)$, epithelial thickness $(\mu \mathrm{m})$, presence of stromal microneuromas (spindle, lateral, and stump neuromas), and grading of keratocyte activation (none, mild, moderate, and severe). Keratocyte activation was defined as cellular changes (hyper-reflective nuclei, visible cytoplasmic processes) and graded by location (anterior, mid, and posterior stroma) and frequency. Individuals with ocular pain had significant lower subbasal nerve densities compared to controls (16.2 vs. $20.1 ; p<0.008)$. In addition, all 27 eyes with ocular pain had microneuromas in their stromal nerves (mean 4.59 per eye) which were not seen in any controls. Finally, all eyes with ocular pain had keratocyte activation (severe in $14.8 \%$, moderate in $25.9 \%$, and mild in $59.3 \%$ ), which was not seen in controls [45].

In the same study, the 27 eyes with ocular pain were grouped by response to topical anesthesia ("no improvement of symptoms" [ $n=20$ eyes] vs. "marked improvement of symptoms" $[n=7$ eyes]). Individuals with no pain after topical anesthesia had significantly higher numbers of stromal microneuromas than those with persistent pain (9.3 vs. 3.0; $p<0.0001)$. Interestingly, no difference in central or peripheral corneal sensation measured by Cochet-Bonnet aesthesiometry was found between the two groups [45]. These data support the paradigm that persistent pain after anesthesia suggests a central (or non-ocular surface) source of pain while elimination of 
pain suggests peripheral nerve abnormalities. The data also highlight that corneal sensitivity alone cannot distinguish between peripheral and central sources of pain.

In a similar study at the Massachusetts Eye and Ear Infirmary, 16 individuals with symptoms of severe photophobia but no ocular surface abnormalities were compared to 16 controls without photophobia. In this study, however, IVCM was used to detect microneuromas in the sub-basal nerve plexus and not the stroma, which were described as abrupt stumplike swellings of injured nerve endings and neurite sprouting [96]. Sub-basal microneuromas were present in $62.5 \%$ of individuals with ocular surface pain compared to $0 \%$ of controls [96]. These findings suggest that microneuromas may be a marker of peripheral nerve abnormalities in individuals with ocular surface pain. Limitations of confocal microscopy include the need for trained operators to acquire high-quality scans, the need for contact between the instrument and the eye, lack of age-adjusted nomograms for corneal nerve density, and the lack of built-in software to quantify nerves and identify features such as keratocyte activation and microneuromas. Furthermore, it is difficult to re-image the exact location on follow-up and, coupled with the dynamic nature of nerves, it is therefore difficult to monitor changes over time.

\section{APPROACH TO TREATMENT}

Management of ocular surface pain depends on the underlying etiology. In cases of nociceptive pain (i.e., trauma, anatomical abnormalities, tear film instability, infection), treatment of the underlying condition will frequently lead to prompt resolution of pain [21]. In individuals with ongoing ocular surface inflammation and damage (e.g., Sjögren's, GVHD), topical antiinflammatories, blood products, and contact lenses are often utilized to help manage pain [2].

Recently, an intranasal electrical neurostimulation device, TrueTear (Allergan, San Diego, CA, USA), was approved for increasing tear production in individuals with DE. This handheld neurostimulation device uses two prongs applied at 45 degrees in the nostrils for $30-60 \mathrm{~s}$ of stimulation to activate the nasolacrimal reflex. In a study of 75 individuals with DE symptoms (all DEQ5 $\geq 6$; mean DEQ5 = 14.9), one intranasal neurostimulation session using TrueTear increased tear volume (mean increase of $13.4 \pm 8.0 \mathrm{~mm} ; p<0.0005)$ and reduced ocular pain (NRS 0-10: mean decrease of $1.48 \pm 2.41 ; p<0.0005)$ compared to baseline. Interestingly, changes in tear volume and ocular pain were independent of one another $(r=0.07, p=0.56)$, and those individuals with low-moderate amounts of pain had the greatest amount of symptom reduction [97]. This study demonstrates the potential for intranasal stimulation to improve ocular pain symptoms in some individuals with DE symptoms.

Treatment for neuropathic ocular pain should be considered when nociceptive therapies fail and in individuals with appropriate symptoms, risk factors, and clinical testing results. In cases of suspected peripheral neuropathic pain, local therapies may be considered, including topical corticosteroids (i.e., loteprednol) or nonsteroidal anti-inflammatory drugs (i.e., dicloflenac) [37], topical cyclosporine or lifitegrast [98], and autologous serum tears $[96,99]$. Patients complaining of evaporation hypersensitivity may response therapeutically to lubricants, goggles, soft and hard contact lenses, prosthetic replacement of the ocular surface ecosystem (PROSE), or punctal occlusion [2].

Refractory peripheral symptoms and mixed and central neuropathic pain merit systemic medical treatment. Gabapentin and pregabalin $(\alpha 2 \gamma$ ligands that modulate central calcium channels) have been used in this regard at doses of 600 and 900 three times daily and 150 twice daily, respectively, with renal dose adjustments in those with creatine clearance $<60 \mathrm{~mL} / \mathrm{min}$ $[100,101]$. In a retrospective case study of eight individuals with severe chronic ocular pain presumed to be due to neuropathic mechanisms (i.e., persistent ocular pain after topical anesthetic, symptoms of photophobia and burning, no adequate response to therapies targeting the ocular surface and tears), gabapentin and pregabalin treatments were given starting at low 
doses (300 mg daily for gabapentin and 25-75 mg daily for pregabalin) and escalated as needed. Two individuals reported complete ocular pain relief on oral medication (NRS $=0$ on a 0-10 scale), three reported significant pain improvements (NRS $\leq 2$ ), one reported slight but noticeable improvement (NRS $=10$ at baseline, 7 at follow-up), and two reported no improvement in pain [100]. This study suggests that $\alpha 2 \gamma$ ligands may be applied to the treatment of chronic ocular surface pain, as they have been successfully used for the treatment of many other types of chronic pain syndromes [102]. Gabapentin and pregabalin are frequently combined with other agents, including serotonin-norepinephrine reuptake inhibitors, such as oral duloxetine 20-60 mg daily [21].

Tricyclic antidepressants, such as nortriptyline $(10-100 \mathrm{mg})$, have also been used to treat individuals with chronic ocular surface pain, alone or in a combination regimen with $\alpha 2 \gamma$ ligands [103]. In a retrospective study, 25 individuals clinically diagnosed with refractory neuropathic corneal pain were treated with nortriptyline (10-100 mg) at Tufts Medical Center. Mean follow-up pain scores (NRS 0-10) were lower 4 weeks post treatment than at pretreatment $(3.8 \pm 2.4$ vs. $6.4 \pm 2.2 ; p<0.0001)$, with pain improvement reported in $84 \%$ of patients $(n=21)$. Specifically, $28 \%$ reported $>$ $50 \%$ improvement $(n=7), 40 \%$ reported $25-50 \%$ improvement $(n=10)$, and $32 \%$ reported $<25 \%$ improvement $(n=8)$ [103]. Taken together, these studies suggest that medications used to treat non-ocular pain can be applied to the treatment of ocular pain. In this regard, there are other agents that are used to treat chronic pain that have not been specifically tested but may also be beneficial in treating chronic ocular surface pain, such as antiepileptics (i.e., topiramate, carbamazepine) and analgesics (i.e., mexiletine) [37, 104].

Adjuvant therapies that are used to treat non-ocular pain have also been applied to the treatment of ocular surface pain. For example, transcutaneous electrical nerve stimulation (TENS) delivers electrical stimuli at the level of the peripheral nerves and has been used as an adjuvant treatment for multiple chronic pain conditions, including facial pain $[105,106]$. Our group investigated the use of the RS-4i Plus Sequential Stimulator (RS-4i; RS Medical, Vancouver, WA, USA) in the treatment of ocular pain by placing two pairs of electrodes above the brow and at the temple bilaterally to generate an interferential current $[105,107]$. In this study, 14 individuals with chronic ocular pain ( $\geq 3$ months) with a suspected neuropathic component (i.e., discordance between significant ocular symptoms of burning or photophobia and minimal ocular surface signs) were treated in an open-label fashion with a one 30-min treatment. Mean pain intensity was significantly reduced 5 min post treatment as compared to pretreatment (0-10 NRS: right eye $4.5 \pm 3.2$ to $1.9 \pm 2.5 \quad[p=0.01] ; \quad$ left eye $4.5 \pm 3.4$ to $2.0 \pm 2.4[p=0.01])$ [105]. The feasibility of using TENS for the long-term treatment of ocular surface pain was investigated in another study of ten individuals followed for a mean of $6.6 \pm 3.6$ months. All ten individuals were able to incorporate the TENS unit into their ocular pain treatment for at least 3 months (with all reporting continued TENS use at last point of contact) and, overall, ocular pain scores decreased with the use of TENS compared to baseline (5.6 vs. $7.6 ; p=0.02$ ) [108]. The results of this study substantiate the positive effect of including non-pharmacologic adjuvants in the long-term management of refractory chronic ocular surface pain.

Botulinum toxin type A (BoNT-A) has also been investigated as an adjuvant treatment for ocular surface pain [109]. CGRP is a known inflammatory neuropeptide found on the ocular surface [20], and BoNT-A is thought to interfere with the release of CGRP and other similar mediators [109]. In a study of 62 individuals with chronic migraine treated with BoNT-A (100-150 units every 3 months based on migraine protocol), BoNT-A not only decreased migraine pain 4-6 weeks post treatment compared to pretreatment but also interictal photophobia $(3.4 \pm 2.5$ vs. $4.9 \pm 3.0$; $p<0.001$ ) and overall light sensitivity (assessed using the Visual Light Symptom Questionnaire [VLSQ]-8 [110]: $\quad 27.7 \pm 6.5$ vs. $29.8 \pm 5.1$; $p=0.002)$. Responses to the questions in the VLSQ-8 questionnaire revealed improvements in frequency of glare $(2.9 \pm 1.3$ vs. $3.4 \pm 0.86$; 
$p=0.001)$, light sensitivity from flickering lights or bright colors $(3.1 \pm 1.3$ vs. $3.7 \pm 1.0$; $p=0.004$ ), and severity of worst period of photophobia $(3.7 \pm 1.0$ vs. $4.2 \pm 0.88 ; p=0.001)$ in the past month [111]. Interestingly, these findings were independent of tear volume, again suggesting that ocular surface findings do not drive ocular surface pain in many individuals. In this regard, other agents that block CGRP, such as erenumab, eptinezumab, galcanezumab, fremanezumab, may also have a beneficial effect on chronic ocular pain $[112,113]$. However, this strategy remains to be tested.

Periocular nerve blockade (supraorbital, supratrochlear, infraorbital, infratrochlear nerve pathways) [100] is another invasive treatment option that has been used to treat chronic ocular pain. In one study, a corticosteroid/anesthetic combination (i.e., $4 \mathrm{~mL} \mathrm{0.5 \%}$ bupivacaine mixed with $1 \mathrm{~mL} \quad 80 \mathrm{mg} / \mathrm{mL}$ methylprednisolone acetate) was injected around one or more periocular nerves in 11 individuals with chronic ocular surface pain. Improvement of pain was noted in seven individuals, with no change reported in the remaining four. These improvements were variable, lasting from hours to months [100]. In addition to other case reports [21, 100, 114], this study supports the use of periocular nerve blocks in the management of refractory ocular surface pain.

More invasive measures may be required in the treatment of refractive pain, including blockade of sphenopalatine and superior cervical ganglions and implantation of long-term devices. For example, one case demonstrated improvement in refractory ocular surface pain following the implantation of a stimulating trigeminal ganglion electrode and high cervical intrathecal pain pump (consisting of bupivacaine and low-dose fentanyl) [115]. This report highlights the morbidity and suffering caused by ocular surface pain, in that an individual was willing undergo such invasive measures to attempt pain relief.

Acupuncture has been investigated as an adjunctive treatment for ocular surface pain. In a prospective study in Pittsburgh (PA), individuals with DE (based on prior DE diagnosis and a score of $\geq 1$ on an 0-4 NRS for any ocular symptom [e.g., discomfort, dryness, scratchiness, burning] that persisted $>1$ month) were grouped into acupuncture $(n=24)$ and sham groups $(n=25)$. The acupuncture protocol consisted of 12 needles in total (i.e., 6 on the bilateral ears, 6 on the bilateral index fingers) left in place for $45 \mathrm{~min}$. The sham treatment consisted of eight needles in total (on the bilateral upper shoulders outside of known acupuncture points). The active treatment group (baseline OSDI $34 \pm 17$ ) demonstrated significant improvements in symptoms at 1 week $(19 \pm 17 ; p<0.01), 1$ month $(21 \pm 17$; $p<0.05)$, 3 months $(20 \pm 21 ; p<0.05)$, and 6 months $(16 \pm 12 ; p<0.01)$. Improvements were also noted in the sham group, although to a smaller degree, from a baseline OSDI of $36 \pm 20$ to lower scores at 1 week $(24 \pm 22), 1$ month $(24 \pm 21), 3$ months $(21 \pm 20)$, and 6 months $(25 \pm 18)$ [116]. Further data regarding the efficacy of acupuncture in the treatment of ocular surface pain areneeded, given its use in treating other neuropathic pain conditions $[37,117]$.

Given the close association of chronic ocular surface pain with psychological discomfort, poor coping mechanisms [11], mood disorders, and QoL factors, cognitive-behavioral therapy (CBT) should be considered in individuals suffering from chronic pain $[4,118]$. While no data have evaluated the efficacy of CBT in chronic ocular surface pain, studies have demonstrated CBT to be a viable treatment adjuvant in nonocular pain conditions [102, 119]. In a multicenter randomized controlled trial in England, 598 adults with subacute or chronic low-back pain were separated into a randomly selected CBT-intervention group $(n=399)$ and control group $(n=199)$, with both groups receiving advice for low-back pain management. At the 12-month analysis, the modified Von Korff pain scale (range 0-100\%) was used to show significant improvements in back pain in the CBT plus advice group compared to the control group (mean pain scale decrease by 13.8 vs. 5.4\%; $p<0.0001$ ) [119]. Another study pooled four RCTs of CBT in fibromyalgia patients in a metaanalysis. CBT in fibromyalgia patients as compared to usual care or a waitlist resulted in small 
improvements in pain (range 0-10 NRS) within 6 months of follow-up (pooled difference -0.62 , 95\% confidence interval -1.08 to - 0.14) [102]. These studies support the use of CBT as an adjuvant treatment in individuals with chronic ocular surface pain.

\section{CONCLUSION}

Chronic ocular surface pain can arise from a number of abnormalities including ongoing tissue injury as well as peripheral and central neurologic mechanisms. A first step in approaching patients is a comprehensive evaluation looking for sources of pain. In individuals with a suspected neuropathic component to pain, an interdisciplinary approach is critical, considering psychological, behavioral, and neurologic contributors. Easing the burden of chronic ocular pain requires further exploration of its neurophysiology, diagnostic modalities, and treatment strategies.

\section{ACKNOWLEDGEMENTS}

Funding. This research was supported by the Department of Veterans Affairs, Veterans Health Administration, Office of Research and Development, Clinical Sciences Research I01 CX002015 (A. Galor), Biomedical Laboratory R\&D (BLRD) Service I01 BX004893 (A. Galor), Department of Defense GW190010 (A. Galor), R01EY026174 (A. Galor), NIH Center Core Grant P30EY014801 and Research to Prevent Blindness Unrestricted Grant. No funding or sponsorship was received for the publication of this article.

Authorship. All named authors meet the International Committee of Medical Journal Editors (ICMJE) criteria for authorship for this article, take responsibility for the integrity of the work as a whole, and have given their approval for this version to be published.
Disclosures. Divy Mehra, Noah K Cohen, and Anat Galor declare that they have no conflict of interest.

Compliance with Ethics Guidelines. This article is based on previously conducted studies and does not contain any studies with human participants or animals performed by any of the authors.

Open Access. This article is licensed under a Creative Commons Attribution-NonCommercial 4.0 International License, which permits any non-commercial use, sharing, adaptation, distribution and reproduction in any medium or format, as long as you give appropriate credit to the original author(s) and the source, provide a link to the Creative Commons licence, and indicate if changes were made. The images or other third party material in this article are included in the article's Creative Commons licence, unless indicated otherwise in a credit line to the material. If material is not included in the article's Creative Commons licence and your intended use is not permitted by statutory regulation or exceeds the permitted use, you will need to obtain permission directly from the copyright holder. To view a copy of this licence, visit http://creativecommons.org/licenses/by$\mathrm{nc} / 4.0 /$.

\section{REFERENCES}

1. Kalangara JP, Galor A, Levitt RC, et al. Characteristics of ocular pain complaints in patients with idiopathic dry eye symptoms. Eye Contact Lens. 2017;43(3):192-8.

2. Jacobs DS. Diagnosis and treatment of ocular pain: the ophthalmologist's perspective. Curr Ophthalmol Rep. 2017;5(4):271-5.

3. International Association for the Study of Pain. IASP terminology. 2020 (updated 14 Dec 2017). https:// www.iasp-pain.org/Education/Content.aspx?Item Number=1698. Accessed 20 Apr 2020.

4. Galor A, Moein HR, Lee C, et al. Neuropathic pain and dry eye. Ocul Surf. 2018;16(1):31-44.

5. Vehof J, Sillevis Smitt-Kamminga N, Kozareva D, Nibourg SA, Hammond CJ. Clinical characteristics 
of dry eye patients with chronic pain syndromes. Am J Ophthalmol. 2016;162(59-65):e2.

6. Galor A, Covington D, Levitt AE, et al. Neuropathic ocular pain due to dry eye is associated with multiple comorbid chronic pain syndromes. J Pain. 2016;17(3):310-8.

7. Goyal S, Hamrah P. Understanding neuropathic corneal pain-gaps and current therapeutic approaches. Semin Ophthalmol. 2016;31(1-2):59-70.

8. Yu J, Asche CV, Fairchild CJ. The economic burden of dry eye disease in the United States: a decision tree analysis. Cornea. 2011;30(4):379-87.

9. Pouyeh B, Viteri E, Feuer W, et al. Impact of ocular surface symptoms on quality of life in a United States veterans affairs population. Am J Ophthalmol. 2012;153(6):1061-6.

10. Galor A, Seiden BE, Park JJ, et al. The association of dry eye symptom severity and comorbid insomnia in US veterans. Eye Contact Lens. 2018;44(Suppl 1): S118-24.

11. Patel S, Felix ER, Levitt RC, Sarantopoulos CD, Galor A. Dysfunctional coping mechanisms contribute to dry eye symptoms. J Clin Med. 2019;8:6.

12. Chia EM, Mitchell P, Rochtchina E, Lee AJ, Maroun R, Wang JJ. Prevalence and associations of dry eye syndrome in an older population: the Blue Mountains Eye Study. Clin Exp Ophthalmol. 2003;31(3): 229-32.

13. McCarty CA, Bansal AK, Livingston PM, Stanislavsky YL, Taylor HR. The epidemiology of dry eye in Melbourne, Australia. Ophthalmology. 1998;105(6):1114-9.

14. Vehof J, Kozareva D, Hysi PG, et al. Relationship between dry eye symptoms and pain sensitivity. JAMA Ophthalmol. 2013;131(10):1304-8.

15. Schiffman RM, Christianson MD, Jacobsen G, Hirsch JD, Reis BL. Reliability and validity of the ocular surface disease index. Arch Ophthalmol. 2000;118(5):615-21.

16. Schaumberg DA, Sullivan DA, Buring JE, Dana MR. Prevalence of dry eye syndrome among US women. Am J Ophthalmol. 2003;136(2):318-26.

17. Schaumberg DA, Dana R, Buring JE, Sullivan DA. Prevalence of dry eye disease among US men: estimates from the Physicians' Health Studies. Arch Ophthalmol. 2009;127(6):763-8.

18. Andersen HH, Yosipovitch G, Galor A. Neuropathic symptoms of the ocular surface: dryness, pain, and itch. Curr Opin Allergy Clin Immunol. 2017;17(5): 373-81.

19. Bandeen-Roche K, Munoz B, Tielsch JM, West SK, Schein OD. Self-reported assessment of dry eye in a population-based setting. Invest Ophthalmol Vis Sci. 1997;38(12):2469-75.

20. Belmonte C, Acosta MC, Merayo-Lloves J, Gallar J. What causes eye pain? Curr Ophthalmol Rep. 2015;3(2):111-21.

21. Dermer H, Lent-Schochet D, Theotoka D, et al. A review of management strategies for nociceptive and neuropathic ocular surface pain. Drugs. 2020;80(6):547-71.

22. Gomes JAP, Azar DT, Baudouin C, et al. TFOS DEWS II iatrogenic report. Ocul Surf. 2017;15(3):511-38.

23. Chhadva P, Alexander A, McClellan AL, McManus KT, Seiden B, Galor A. The impact of conjunctivochalasis on dry eye symptoms and signs. Invest Ophthalmol Vis Sci. 2015;56(5):2867-71.

24. Bron AJ, de Paiva CS, Chauhan SK, et al. TFOS DEWS II pathophysiology report. Ocular Surface. 2017;15(3):438-510.

25. Li Z, Fu T, Li L, et al. Prevalence, severity, and predictors of dry eye and dry mouth in Chinese patients with primary Sjögren syndrome. Clin Rheumatol. 2018;37(11):2971-9.

26. Adatia FA, Michaeli-Cohen A, Naor J, Caffery B, Bookman A, Slomovic A. Correlation between corneal sensitivity, subjective dry eye symptoms and corneal staining in Sjogren's syndrome. Can J Ophthalmol. 2004;39(7):767-71.

27. Aykut V, Elbay A, Çigdem Uçar I, et al. Corneal sensitivity and subjective complaints of ocular pain in patients with fibromyalgia. Eye (Lond.). 2018;32(4):763-7.

28. Whitcher JP Jr, Gritz DC, Daniels TE. The dry eye: a diagnostic dilemma. Int Ophthalmol Clin. 1998;38(4):23-37.

29. Mian SI, De la Parra-Colín P, De Melo-Franco R, Johnson C, Barrientos-Gutierrez T. Dry eye disease incidence associated with chronic graft-host disease: nonconcurrent cohort study (An American Ophthalmological Society Thesis). Trans Am Ophthalmol Soc. 2015;113:11.

30. [No authors listed]. Methodologies to diagnose and monitor dry eye disease: report of the Diagnostic Methodology Subcommittee of the International Dry Eye WorkShop (2007). Ocul Surf. 2007;5(2): 108-52 
31. Lu R, Huang R, Li K, et al. The influence of benign essential blepharospasm on dry eye disease and ocular inflammation. Am J Ophthalmol. 2014;157(3):591-7.

32. Kinard KI, Smith AG, Singleton JR, et al. Chronic migraine is associated with reduced corneal nerve fiber density and symptoms of dry eye. Headache. 2015;55(4):543-9.

33. Farhangi M, Feuer W, Galor A, et al. Modification of the neuropathic pain symptom inventory for use in eye pain (NPSI-Eye). Pain. 2019;160(7):1541-50.

34. Farhangi M, Diel RJ, Buse DC, et al. Individuals with migraine have a different dry eye symptom profile than individuals without migraine. $\mathrm{Br} \mathrm{J}$ Ophthalmol. 2020;104(2):260-4.

35. Crane AM, Levitt RC, Felix ER, Sarantopoulos KD, McClellan AL, Galor A. Patients with more severe symptoms of neuropathic ocular pain report more frequent and severe chronic overlapping pain conditions and psychiatric disease. Br J Ophthalmol. 2017;101(2):227.

36. Schuster AKG, Wettstein M, Gerhardt A, Eich W, Bieber C, Tesarz J. Eye pain and dry eye in patients with fibromyalgia. Pain Med. 2018;19(12):2528-35.

37. Dieckmann G, Goyal S, Hamrah P. Neuropathic corneal pain: approaches for management. Ophthalmology. 2017;124(11):S34-47.

38. Rosenthal P, Borsook D. Ocular neuropathic pain. Br J Ophthalmol. 2016;100(1):128.

39. Bangash TH. Trigeminal neuralgia: frequency of occurrence in different nerve branches. Anesth Pain Med. 2011;1(2):70-2.

40. Skalicky SE, Goldberg I, McCluskey P. Ocular surface disease and quality of life in patients with glaucoma. Am J Ophthalmol. 2012;153(1):1-9.e2.

41. Hovanesian JA, Shah SS, Maloney RK. Symptoms of dry eye and recurrent erosion syndrome after refractive surgery. J Cataract Refract Surg. 2001;27(4):577-84.

42. Tirpack AR, Vanner E, Parrish JM, Galor A, Hua H-U, Wellik SR. Dry eye symptoms and ocular pain in veterans with glaucoma. J Clin Med. 2019;8(7): 1076.

43. Levitt AE, Galor A, Weiss JS, et al. Chronic dry eye symptoms after LASIK: parallels and lessons to be learned from other persistent post-operative pain disorders. Mol Pain. 2015;11:21.

44. Hays RD, Tarver ME, Spritzer KL, et al. Assessment of the psychometric properties of a questionnaire assessing patient-reported outcomes with laser in situ Keratomileusis (PROWL). JAMA Ophthalmol. 2017;135(1):3-12.

45. Ross AR, Al-Aqaba MA, Almaazmi A, et al. Clinical and in vivo confocal microscopic features of neuropathic corneal pain. $\mathrm{Br} \mathrm{J}$ Ophthalmol. 2020;104(6):768-75.

46. Theophanous C, Jacobs DS, Hamrah P. Corneal Neuralgia after LASIK. Optom Vis Sci. 2015;92(9): e233-e240240.

47. Hwang SH, Choi YH, Paik HJ, Wee WR, Kim MK, Kim DH. Potential importance of ozone in the association between outdoor air pollution and dry eye disease in South Korea. JAMA ophthalmology. 2016;134(5):503-10.

48. Novaes P, Saldiva PH, Matsuda M, et al. The effects of chronic exposure to traffic derived air pollution on the ocular surface. Environ Res. 2010;110(4): $372-4$.

49. Kim Y, Paik HJ, Kim MK, Choi YH, Kim DH. Shortterm effects of ground-level ozone in patients with dry eye disease: a prospective clinical study. Cornea. 2019;38(12):1483-8.

50. Rosenthal P, Borsook D. The corneal pain system. Part I: the missing piece of the dry eye puzzle. Ocul Surf. 2012;10(1):2-14.

51. Ferrari G, Nallasamy N, Downs H, Dana R, Oaklander AL. Corneal innervation as a window to peripheral neuropathies. Exp Eye Res. 2013;113: 148-50.

52. Dubin AE, Patapoutian A. Nociceptors: the sensors of the pain pathway. J Clin Invest. 2010;120(11): 3760-72.

53. Belmonte C, Gallar J. Cold thermoreceptors, unexpected players in tear production and ocular dryness sensations. Invest Ophthalmol Vis Sci. 2011;52(6):3888-922.

54. Hirata H, Okamoto K, Tashiro A, Bereiter DA. A novel class of neurons at the trigeminal subnucleus interpolaris/caudalis transition region monitors ocular surface fluid status and modulates tear production. J Neurosci. 2004;24(17):4224-322.

55. Tashiro A, Okamoto K, Chang Z, Bereiter DA. Behavioral and neurophysiological correlates of nociception in an animal model of photokeratitis. Neuroscience. 2010;169(1):455-62.

56. Galor A, Levitt RC, Felix ER, Martin ER, Sarantopoulos CD. Neuropathic ocular pain: an important yet underevaluated feature of dry eye. Eye (Lond.). 2015;29(3):301-12. 
57. Lele PP, Weddell G. Sensory nerves of the cornea and cutaneous sensibility. Exp Neurol. 1959;1: 334-59.

58. Muller LJ, Marfurt CF, Kruse F, Tervo TM. Corneal nerves: structure, contents and function. Exp Eye Res. 2003;76(5):521-42.

59. Belmonte C, Nichols JJ, Cox SM, et al. TFOS DEWS II pain and sensation report. Ocul Surf. 2017;15(3): 404-37.

60. Hirata H, Meng ID. Cold-sensitive corneal afferents respond to a variety of ocular stimuli central to tear production: implications for dry eye disease. Invest Ophthalmol Vis Sci. 2010;51(8):3969-76.

61. Bron R, Wood RJ, Brock JA, Ivanusic JJ. Piezo2 expression in corneal afferent neurons. J Comp Neurol. 2014;522(13):2967-79.

62. Parra A, Madrid R, Echevarria D, et al. Ocular surface wetness is regulated by TRPM8-dependent cold thermoreceptors of the cornea. Nat Med. 2010;16(12):1396-9.

63. Zhang X, Mak S, Li L, et al. Direct inhibition of the cold-activated TRPM8 ion channel by $\mathrm{G} \alpha_{\mathrm{q}}$. Nat Cell Biol. 2012;14(8):851-8.

64. Lambiase A, Micera A, Pellegrini G, et al. In vitro evidence of nerve growth factor effects on human conjunctival epithelial cell differentiation and mucin gene expression. Invest Ophthalmol Vis Sci. 2009;50(10):4622-30.

65. De Felipe C, Gonzalez GG, Gallar J, Belmonte C. Quantification and immunocytochemical characteristics of trigeminal ganglion neurons projecting to the cornea: effect of corneal wounding. Eur J Pain. 1999;3(1):31-9.

66. Costigan M, Scholz J, Woolf CJ. Neuropathic pain: a maladaptive response of the nervous system to damage. Annu Rev Neurosci. 2009;32:1-32.

67. Pergolizzi J, Ahlbeck K, Aldington D, et al. The development of chronic pain: physiological CHANGE necessitates a multidisciplinary approach to treatment. Curr Med Res Opin. 2013;29(9): 1127-35.

68. Parra A, Gonzalez-Gonzalez O, Gallar J, Belmonte C. Tear fluid hyperosmolality increases nerve impulse activity of cold thermoreceptor endings of the cornea. Pain. 2014;155(8):1481-91.

69. Kurose M, Meng ID. Dry eye modifies the thermal and menthol responses in rat corneal primary afferent cool cells. J Neurophysiol. 2013;110(2): 495-504.
70. Farazifard R, Safarpour F, Sheibani V, Javan M. Eyewiping test: a sensitive animal model for acute trigeminal pain studies. Brain Res Brain Res Protoc. 2005;16(1-3):44-9.

71. Moulton EA, Becerra L, Rosenthal P, Borsook D. An approach to localizing corneal pain representation in human primary somatosensory cortex. PLoS ONE. 2012;7(9):e44643.

72. McCarson KE, Enna SJ. Nociceptive regulation of $\mathrm{GABA}(\mathrm{B})$ receptor gene expression in rat spinal cord. Neuropharmacology. 1999;38(11):1767-73.

73. Sandkühler J. Models and mechanisms of hyperalgesia and allodynia. Physiol Rev. 2009;89(2): 707-58.

74. Wen Y-R, Tan P-H, Cheng J-K, Liu Y-C, Ji R-R. Microglia: a promising target for treating neuropathic and postoperative pain, and morphine tolerance. J Formos Med Assoc. 2011;110(8):487-94.

75. Hirata H, Hu JW, Bereiter DA. Responses of medullary dorsal horn neurons to corneal stimulation by CO(2) pulses in the rat. J Neurophysiol. 1999;82(5): 2092-107.

76. Rosenthal P, Baran I, Jacobs DS. Corneal pain without stain: is it real? Ocular Surf. 2009;7(1): $28-40$.

77. von Hehn CA, Baron R, Woolf CJ. Deconstructing the neuropathic pain phenotype to reveal neural mechanisms. Neuron. 2012;73(4):638-52.

78. Hirata H, Okamoto K, Bereiter DA. GABA(A) receptor activation modulates corneal unit activity in rostral and caudal portions of trigeminal subnucleus caudalis. J Neurophysiol. 2003;90(5):2837-49.

79. Glover GH. Overview of functional magnetic resonance imaging. Neurosurg Clin N Am. 2011;22(2): 133.

80. Moulton EA, Becerra L, Borsook D. An fMRI case report of photophobia: activation of the trigeminal nociceptive pathway. Pain. 2009;145(3):358-63.

81. Bomfim Pereira MG, Rodrigues MA, Carvalho Rodrigues SA. Eyelid entropion. Semin Ophthalmol. 2010;25(3):52-8.

82. de Menezes Bedran EG, Correia Pereira MV, Bernardes TF. Ectropion. Semin Ophthalmol. 2010;25(3):59-655.

83. Correia Pereira MV, Firmato Glória AL. Lagophthalmos. Semin Ophthalmol. 2010;25(3):72-8.

84. Chhadva P, McClellan AL, Alabiad CR, Feuer WJ, Batawi H, Galor A. Impact of eyelid laxity on 
symptoms and signs of dry eye disease. Cornea. 2016;35(4):531-5.

85. Wilkin J, Dahl M, Detmar M, et al. Standard classification of rosacea: report of the national rosacea society expert committee on the classification and staging of Rosacea. J Am Acad Dermatol. 2002;46(4):584-7.

86. Lin P, Kitaguchi Y, Mupas-Uy J, Sabundayo MS, Takahashi Y, Kakizaki H. Involutional lower eyelid entropion: causative factors and therapeutic management. Int Ophthalmol. 2019;39(8):1895-907.

87. Bouhassira D, Attal N, Fermanian J, et al. Development and validation of the neuropathic pain symptom Inventory. Pain. 2004;108(3):248-57.

88. Qazi Y, Hurwitz S, Khan S, Jurkunas UV, Dana R, Hamrah P. Validity and reliability of a novel ocular pain assessment survey (OPAS) in quantifying and monitoring corneal and ocular surface pain. Ophthalmology. 2016;123(7):1458-68.

89. Shaheen BS, Bakir M, Jain S. Corneal nerves in health and disease. Surv Ophthalmol. 2014;59(3): 263-85.

90. Milner MS, Beckman KA, Luchs JI, et al. Dysfunctional tear syndrome: dry eye disease and associated tear film disorders-new strategies for diagnosis and treatment. Curr Opin Ophthalmol. 2017;27(Suppl $1): 3-47$.

91. Stapleton F, Tan ME, Papas EB, et al. Corneal and conjunctival sensitivity to air stimuli. Br J Ophthalmol. 2004;88(12):1547-51.

92. Bourcier T, Acosta MC, Borderie V, et al. Decreased corneal sensitivity in patients with dry eye. Invest Ophthalmol Vis Sci. 2005;46(7):2341-5.

93. Spierer O, Felix ER, McClellan AL, et al. Corneal mechanical thresholds negatively associate with dry eye and ocular pain symptoms. Invest Ophthalmol Vis Sci. 2016;57(2):617-25.

94. Crane AM, Feuer W, Felix ER, et al. Evidence of central sensitisation in those with dry eye symptoms and neuropathic-like ocular pain complaints: incomplete response to topical anaesthesia and generalised heightened sensitivity to evoked pain. Br J Ophthalmol. 2017;101(9):1238-43.

95. Cruzat A, Qazi Y, Hamrah P. In vivo confocal microscopy of corneal nerves in health and disease. Ocular Surf. 2017;15(1):15-47.

96. Aggarwal S, Kheirkhah A, Cavalcanti BM, et al. Autologous serum tears for treatment of photoallodynia in patients with corneal neuropathy: efficacy and evaluation with in vivo confocal microscopy. Ocular Surf. 2015;13(3):250-62.

97. Farhangi M, Cheng AM, Baksh B, et al. Effect of non-invasive intranasal neurostimulation on tear volume, dryness and ocular pain. Br J Ophthalmol. 2019. https://doi.org/10.1136/bjophthalmol-2019315065

98. Holland EJ, Luchs J, Karpecki PM, et al. Lifitegrast for the treatment of dry eye disease: results of a phase III, randomized, double-masked, placebocontrolled trial (OPUS-3). Ophthalmology. 2017;124(1):53-60.

99. Soleimani M, Tabatabaei SA, Mahmoudzadeh R. Use of autologous serum tears for the treatment of ocular surface disease from patients with systemic autoimmune diseases. Am J Ophthalmol. 2019;199: 261-2.

100. Small LR, Galor A, Felix ER, Horn DB, Levitt RC, Sarantopoulos CD. Oral gabapentinoids and nerve blocks for the treatment of chronic ocular pain. Eye \& Contact Lens. 2020;46(3):174-81.

101. Raouf M, Atkinson TJ, Crumb MW, Fudin J. Rational dosing of gabapentin and pregabalin in chronic kidney disease. J Pain Res. 2017;10:275-8.

102. Skelly AC, Chou R, Dettori JR, et al. AHRQ comparative effectiveness reviews. Noninvasive nonpharmacological treatment for chronic pain: a systematic review update. Rockville: Agency for Healthcare Research and Quality; 2020.

103. Ozmen MC, Dieckmann G, Rashad R, et al. Nortriptyline is effective in ameliorating symptoms of neuropathic corneal pain. Investig Ophthalmol Vis Sci. 2019;60(9):4732.

104. Challapalli V, Tremont-Lukats IW, McNicol ED, Lau J, Carr DB. Systemic administration of local anesthetic agents to relieve neuropathic pain. Cochrane Database Syst Rev. 2005;2005(4):CD003345.

105. Sivanesan E, Levitt RC, Sarantopoulos CD, Patin D, Galor A. Noninvasive electrical stimulation for the treatment of chronic ocular pain and photophobia. neuromodulation: Technol Neural Interface. 2018;21(8):727-34.

106. Holt CR, Finney JW, Wall CL. The use of transcutaneous electrical nerve stimulation (TENS) in the treatment of facial pain. Ann Acad Med Singapore. 1995;24(1):17-22.

107. Tabasam G, Johnson MI. The use of interferential therapy for pain management by physiotherapists. Int J Therapy Rehabil. 2006;13(8):357-64. 
108. Zayan K, Aggarwal S, Felix E, Levitt R, Sarantopoulos $\mathrm{K}$, Galor A. Transcutaneous electrical nerve stimulation for the long-term treatment of ocular pain. Neuromodulation. 2020. https://doi.org/10.1111/ ner.13146.

109. Venkateswaran N, Hwang J, Rong A, et al. Onabotulinum toxin A improves photophobia and sensations of dryness independent of ocular surface parameters. Investig Ophthalmol Vis Sci. 2019;60(9):6757.

110. Verriotto JD, Gonzalez A, Aguilar MC, et al. New methods for quantification of visual photosensitivity threshold and symptoms. Transl Vis Sci Technol. 2017;6(4):18.

111. Diel RJ, Hwang J, Kroeger ZA, et al. Photophobia and sensations of dryness in patients with migraine occur independent of baseline tear volume and improve following botulinum toxin $\mathrm{A}$ injections. $\mathrm{Br}$ J Ophthalmol. 2019;103(8):1024-9.

112. Huang IH, Wu P-C, Lin E-Y, Chen C-Y, Kang Y-N. Effects of anti-calcitonin gene-related peptide for migraines: a systematic review with meta-analysis of randomized clinical trials. Int $\mathrm{J}$ Mol Sci. 2019;20(14):3527.

113. Iyengar S, Johnson KW, Ossipov MH, Aurora SK. CGRP and the trigeminal system in migraine. Headache. 2019;59(5):659-81.
114. Duerr ERH, Chang A, Venkateswaran N, et al. Resolution of pain with periocular injections in a patient with a 7-year history of chronic ocular pain. Am J Ophthalmol Case Rep. 2019;14:35-8.

115. Hayek SM, Sweet JA, Miller JP, Sayegh RR. Successful management of corneal neuropathic pain with intrathecal targeted drug delivery. Pain Med. 2015;17(7):1302-7.

116. Dhaliwal DK, Zhou S, Samudre SS, Lo NJ, Rhee MK. Acupuncture and dry eye: current perspectives. A double-blinded randomized controlled trial and review of the literature. Clin Ophthalmol. 2019;13: $731-40$.

117. Ju ZY, Wang K, Cui HS, et al. Acupuncture for neuropathic pain in adults. Cochrane Database Syst Rev. 2017;12(12):CD012057.

118. Zilliox LA. Neuropathic Pain. Continuum (Minneap Minn). 2017;23 (2, Selected Topics in Outpatient Neurology):512-32.

119. Lamb SE, Hansen Z, Lall R, et al. Group cognitive behavioural treatment for low-back pain in primary care: a randomised controlled trial and cost-effectiveness analysis. Lancet. 2010;375(9718):916-23. 